\title{
A Value-based Approach to Unspelling Entrepreneurship
}

\author{
Aleksey Baryshev ${ }^{1}$, Galina Barysheva ${ }^{1 \mathrm{a}}$ \\ ${ }^{1}$ National Research Tomsk Polytechnic University, 634050 Lenin str., 30, Tomsk, Russia
}

\begin{abstract}
Entrepreneurship and the entrepreneur figure are social phenomena subjected to constant mutations. Extant definitions of entrepreneurship are always based on current characteristics of entrepreneur activity and, as a rule, absolutize them as essential. In the article main mystifications of entrepreneurship are analyzed due to the fact that it is attributed general properties of entrepreneurial activity in the way they are understood in a certain historical period. The paper suggests a way out of the succession of mystifications by rejecting the entrepreneurship definition in the frame of a subjectobject interpretive scheme and the development of the entrepreneur activity concept as a kind of social activity. The social action theory and the theory of social objects fetishization are the methodological research foundation. The results of the research are the following. First, the interpretation of the entrepreneur and entrepreneurship on the basis of personal traits, functions and ways of the construction of the future are mystifications ascribing the monopoly on arising and developing human action characteristics in different historical periods to entrepreneurship. Second, the cause of mystifications is the transfer of the human action analysis according to the scheme «subject-processobject» to the research of entrepreneurship. Third, attempts to overcome mystifications while preserving the naturalistic approach result in the multiplication of entrepreneurial mystifications as the reflection of new arising general characteristics of human action. Fourth, a general approach to the definition of the entrepreneurial action as a kind of the social action, which has sense in the value production and is capable of everlasting enrichment with new modus of actions and created values, is suggested. Perspectives of further research include the investigation of synchronic and diachronic peculiarities of entrepreneurial action modus and produced values.
\end{abstract}

\section{Introduction}

Among social characters of the present day society the entrepreneur is one of the most mystified figures. Only the politician figure can compete with her/him in the activity content indeterminacy. Modern notion of the entrepreneur is fuzzy as it includes all active participants of economic processes: from retailers to raw materials oligarchs, from an individual businessperson to a transnational corporation.

Constantly renewing definitions of the essence of the entrepreneurial action differ in ascribing vanguard characteristics to it, later revealed in any kind of constructive human activity. Hence, various interpretations of entrepreneurship, which historical succession develops from most superficial fixations of behaviour peculiarities of its subjects to definitions attempting to reveal concealed determinancy and logic of their actions and, further, to conceptions, reconstructing cognitive mechanisms, which prove that entrepreneurial action results are not predetermined beforehand, but they evolve in the process of dynamic creation, are considered in this work.

The question, which must be asked in this connection, is whether categories of the entrepreneurial action are only anticipations of new definitions of human activity essence in general or the entrepreneurial action has its own content, determining its specific character against the background of other human activities. An approach to find a solution of this issue is undertaken in this research.

\section{Personality-based mystification of entrepreneurship and an entrepreneur figure}

The first mystification of the entrepreneur figure arises when the character is given social and psychological features of a balance disturber, a developer of new useful goods and institutions. J. Schumpeter defines this function of the entrepreneur as creative destruction [1]. Meanwhile a creative entrepreneur component can have a wide range of applications: from criminal services,

\footnotetext{
$\overline{{ }^{a} \text { Corresponding author: ganb@tpu.ru }}$
} 
counterfeit production, shady business structure formation to the production of universally recognized social goods with legal methods [2].

Such a definition of the entrepreneur refers either to individual really existing entrepreneurs or to the aggregate action of the whole entrepreneur class. From the viewpoint of a single-object perspective not all economically active subjects are entrepreneurs, but only those who are at the stage of creative destruction at the moment. Therefore according to Schumpeter, a professional entrepreneur is a rare phenomenon. In case when the entrepreneur population, as a whole, is responsible for the progress, heuristic value of «entrepreneurship» and «entrepreneur» notions becomes less considerable because of the value increase in the collective rationality mechanism in the framework of market competition. Thus, due to this ambiguity of «the entrepreneur» notion this object of social reality is formed not in the scientific discourse, but in the sociopolitical one, supporting its administrative and legal legitimation.

This allows making the conclusion that the industrialmarket economy transformation, promoting the emergence of hightech industry entrepreneurs and business angel investors, freelances, intrapreneurs, social networks architects and other figures with buzzword ranks, has made not such a considerable contribution to the fuzzy of the entrepreneur notion as it was predetermined by its initial ambiguity as far back as in the classical capitalism period. An industrial class representative, a person acting by proxy of the capital, a functioning capitalist - this is the entrepreneur image in socio-economic theories of classical capitalism.

As there were no clear real entrepreneurship identifiers (wage, interest, rent) the classical socioeconomic theory had to search for entrepreneurship referent in personality peculiarities of this character. Significant contribution in the study of entrepreneur personality qualities favourable to entrepreneurial activity was made by the behaviourist school in economy science and psychology. But modern scientists note that there are no specific entrepreneur personality characteristics which are possessed by representatives of other occupations [3]. However, so far curricula of economy training courses of higher education institutions, orientating their graduates to the entrepreneur activity, have included courses dealing with psychological features of the entrepreneur personality.

The approach to the entrepreneur definition on the basis of personality characteristics may be considered personality-fetishistic. It is well-known that the reduction of social characteristics of people to their natural specific features is one of early manifestations of social relations fetishization.

\section{Functionalistic mystification of the entrepreneur}

Fetishization of personal characteristics must be distinguished from consideration of the person as personification of certain social objects. The tradition of taking entrepreneur specificity out of spiritual sphere is based on works of M. Weber and W. Sombart. And basing on modern ideas about «capitalism spirit», one can say that the definition of the entrepreneur suggested by Weber and founded on the specifically historical ethic attitude (Protestant ethics) is rather a particular solution of the issue about the involvement modus of the person in capitalism than an answer to the question about the general social specific character of the entrepreneur activity and her/his social characteristics [4]. According to Sombart, «entrepreneurial spirit» is objectified in the enterprise, which becomes a subject [5]. The interpretation of «entrepreneurial spirit» as a result of its reduction to the enterprise spirit reveals characteristics of commodities fetishism, in which not personal qualities of individuals, but properties of goods produced by them, determine social actions and characteristics of people personifying them. The circle closes: initial creative spirit of the entrepreneur «settles» in the enterprise, thus making the entrepreneur figure easily replaced by another subject of rational management. As a result, the entrepreneur becomes a master of an important episode, but still only an episode in the enterprise life.

Ideas about entrepreneurial spirit as objectified spirit of the enterprise or as a cultural-social activity incentive in relation to the definition of the entrepreneur as a social-economic subject mean functionalistic mystification of the entrepreneur activity derived from fetishism of commodities. The entrepreneur is the person who provides the foundation and functioning of the capitalist enterprise, who is inspired with its spirit and realizes logic of the enterprise advance.

\section{Creative work mystification in entrepreneur activity}

The third mystification, concerning the entrepreneur image, is that he is attributed creative subjectivity that is not directly observed in the world of reified categories of capitalist economy. Paradox of the world of universal reification is that though economy development is dictated by logic of reified conditions and its agents are only their personifications, for real functioning of the system such a subject as the entrepreneur is required. To organize and operate a business means to perform actions on the basis of logic, leaving behind logic of objects motion, to foresee events development in the world of reified forms. The entrepreneur foresees and creates the future. His actions are not kept within the frame of traditional project activity, based on the realization objectively existing possibilities, but they mean the development of new possibilities and, consequently, the creation of the future freely ex nihil.

In such conditions the entrepreneurship theory starts developing based on the notions, denoting the process of creative reality transformation such as judgment[6], alertness[7], empathy[8], effectuation, [9] creative team act[10], social network[11], imagination [12].

New notions, describing a creative component in the entrepreneur activity, on the one hand, demystify old ideas, dealing, first of all, with risks and combination of 
resources as entrepreneur essence, but, on the other hand, they are sources of new mystifications. Let us consider this in detail.

Undoubtedly, a creative-constructivist vision of the entrepreneur «humanizes» the economic system. However, such ideas give birth to a new mystification, which means that the entrepreneur becomes «an economic person in general» or an «economic superman» («cognitive supermen») rising over the whole economic system [13].

The back side of this mystification is that while the economic system is developing, entrepreneurship becomes a characteristic of any activity: «We are all entrepreneurs now, or, at a minimum, we all live in a world in which the unquestioned social value and legitimacy of entrepreneurship shapes public policy, social development, economic futures, and cultural beliefs and expectations» [14], Imre Szeman writes. In such world of «self-entrepreneurship» [15] really all subjects of economic life, according to T.W. Schulz, are entrepreneurs [16].

Ideas about entrepreneurship as a «universal» phenomenon, on the one hand, and «supereconomic», on the other hand, mystify this activity, identifying it with social creativity and personality autopoiesis. In addition to that, entrepreneur capability to foresee and change the run of economic events, set up social networks and communities is not unique for entrepreneurs, but it also characterizes representatives of other creative activity types, such as investigators and inventors. Many social thinkers pointed out this. E. Gellner, for example, in his "Nations and Nationalism" considered the entrepreneur as an economic double of the scientist [17].

A creative-constructivist interpretation of entrepreneurial activity promoted demystification of risks and combinatorial entrepreneur capabilities, which helped to heroize and labourize the entrepreneur in socio-political discourse, and in scientific-economic discourse they were justification of entrepreneurial income as the pay for risks and realization of the resources combination function.

After introducing creativity and, consequently, uncertainty in the analysis, the risk stopped being the exclusive for lot of the entrepreneur. The risk is not less, but may be even more important for the research activity (M. Polanji) and every-day life (I. Szeman) than for business as such.

The theme of risk generality is particularly urgent in the course of the knowledge society establishment, when the risk becomes a reverse side of knowledge. It should be noted that in the present day conditions the entrepreneur is protected, as a rule, by the principle of limited responsibility, which greatly undermines former «monopoly» of this personage for the risk. The aspect of risk generality in the modern society is supplemented with one more criticism line, concerning the application of the risk notion to entrepreneurship as a creative process in uncertainty conditions.

The matter is that the expansion of ideas about the creative character of entrepreneurial activity required to change ideas about the opportunities which are exploited by an entrepreneur. Entrepreneurship not only opens new opportunities, but also creates them. At such cognitive approach the risk notion loses heuristic value, leaving place to the notions of uncertainty and judgment. Decisions, based on judgments concerning evaluations of future events, assume principally unknown distribution of their probable occurrence. As for the risk, it is characterized by known distribution of events probability and is brought to the choice of one of them as distinct from uncertainty [18].

Another difference of the risk and judgmental decision is in the fact that judgments in relation to the configuration and incessant «reshuffling» of capital resources are taken not only when the enterprise is established, but permanently during the process of its functioning [19]. Therefore, now the enterprise, from cognitive viewpoint, consists of decisions, which determine ways of enterprise's functioning. The notion «judgmental decision-making under conditions of uncertainty» promotes filling the entrepreneurship notion with more specific content, makes it the routine work in comparison with the project, dealing with a single or periodic risk.

In addition, everyday subjective judgments and, as a result, taken decisions concerning ways of resource usage, make the enterprise a unique result of one entrepreneur (team) activity and they make resources heterogeneous, not brought to each other as it occurs in neoclassic paradigm. The main resource, i.e. possibility of taking such judgments, turns out to be very specific for subjects of various enterprises and, consequently, heterogeneous. Inside entrepreneurial teams heterogeneity of mental models of particular participants increases as well. In favourable conditions this can result in long-term competitive advantages, based on VRINresources of the firm [20].

Thus, risk demystification results in the quantity increase of internal distinctions in entrepreneurial activity and in the appearance of new mystifications, proclaiming «causal ambiguity» [21] of sources of sustainable competitive advantages [22].

A new mystification, which is developed as a result of transference of the agenda of the entrepreneurial researches into the cognitive plane, means that entrepreneurship becomes an ideal type of human activity in general, with its paradoxes, which are rooted in its creative essence.

Parallel to the risk, the notion of the resources combination and subsequent entrepreneurial income justification are also demystified when uncertainty, judgmental subjectivity and resources heterogeneity are introduced for consideration. Entrepreneurial income (profit) cannot be considered as the pay for entrepreneurial services any longer. For the interpretation of such kind of profit as wage spirit it is necessary for services of entrepreneurial activity to be homogeneous, i.e. should be described incrementally, when their quantity can be supplied in gradually increasing volumes, corresponding with marginal return. However, entrepreneur judgments are heterogenic and subjective, so they cannot be evaluated and paid as a specific kind of services [23]. 
This means that entrepreneurial services are not subjected to the contract in principle and entrepreneur's judgment (decision) can be realized only in the form and in the frames of a new or functioning enterprise. Thus, a new mystification, evolving on the basis of the initial idea about the entrepreneur as a schemer of resources and dealing with a specific object of entrepreneur property, arises. Resources combination in conditions of uncertainty assumes that the entrepreneur is the enterprise owner. «Ownership theories of entrepreneurship start with the proposition that entrepreneurial judgment is costly to trade, an idea originally suggested by Knight (1921). When judgment is complementary to other assets, it makes sense for entrepreneurs to own these complementary assets. The entrepreneur's role, then, is to arrange or organize the capital goods she/he owns. Entrepreneurial judgment is ultimately judgment about the control of resources» [24].

A long history of discussion on the issue whether a true entrepreneur is an owner or not, in our opinion, ignored the object of entrepreneur property as it is. Representatives of Austrian School who support the idea about entrepreneurship according to above mentioned reasoning about heterogeneity and subjectivity of entrepreneur judgments, definitely provide the entrepreneur with status of the owner of enterprise assets. From the viewpoint of J. Schumpeter, I. Kirzner and their followers, who saw the core of entrepreneurship in new possibilities discovery, property is not a necessary attribute of the entrepreneur.

On the other hand, not every owner of factors of production is the entrepreneur. According to political economy foundations property is a means to join factors of production. So, the manager can combine factors only with the owner warrant [25]. However, property by itself does not provide the combination of resources, all the more, in uncertainty conditions and heterogeneity, without a scheme of their joining and everyday subjective decisions concerning its improvement and adaptation.

What property does this subject own, and whose judgments founded mainly on conjectures and personal beliefs constantly change configurations of resources and ways of their use? Obviously she/he is the owner of the very process, presenting itself a heterogeneous combination of subjective knowledge. From this cognitive viewpoint the enterprise is a scheme made up of entrepreneur judgments (decisions), and the entrepreneur is an incontestable owner of this procedural scheme, even if there are only losses and responsibility is limited to minimal value of authorized capital.

Now the entrepreneur really appears to be a «cognitive superman» and even an economic superman. In this new mystification The Entrepreneur as the process owner, opposite from others, may own the functioning process of objects, without possessing these things, and run risks without risking.

\section{Cause and ways of overcoming mystifications in the entrepreneurship theory}

Thus, the demystification process of definitions, existing at the moment, inevitably results in the origin of new mystifications. However, if new ideas break the chain of previous ones, having qualitative difference from them, destructing their genetic sequence, which consists in the development of some fundamental principle of their construction, such action will be rather efficient, providing quite new knowledge about the object. Therefore, it is important to form the entrepreneur notion so that it, first, does not absolutize specific-historical characteristics of entrepreneurial action and, second, embraces a specific character of entrepreneurial action as a social action.

Existing concepts about entrepreneurship demonstrate ideas about human activity in general, often doing this with outstripping in relation to other activity types. Thus, either a heroic character of the entrepreneur or her/his peculiar cognitive abilities, that are not so evident when watching representatives of other occupations, become important.

In the general definition of the entrepreneurship it is important that it is aimed, as the action, at others and in its sense it correlates with actions of others. The result of such action is reflexive and this provides the actor with realization of assumed sense in a definite symbolic form that, in its turn, provides reproduction of her/his socioeconomic characteristics. Transformation of results into a cyclic cause of the action itself means that a general definition of the entrepreneurial activity must characterize it as an autopoetic action regardless of the fact that in specific historical conditions it is understood as a purposeful one that is oriented to the external aim in relation to the system of the action.

At present there are many attempts to formulate the entrepreneurship notion regarding a specific character of the entrepreneurial activity. Various correlations of the action as a process and its result are probable. While goods, innovations and even institutes are often represented as intermediate results, and profit in its various nominations as a final result, but as for the process, entrepreneurial activity is characterized variously: discovery and exploitation of possibilities, development of competitive advantages, creative destruction, imagination, effectuation, decisions, etc.

At present most widespread conceptions of a substantial part of the entrepreneurship are attached to the idea that it results in the development of new resources on the basis of an original combination of traditional ones, this corresponds to the resource-based approach in the strategic theory of a firm, the approach based on knowledge-view and the conception of dynamic capabilities.

These theories do not specially focus on the orientation of the entrepreneurial activity on others and its correlation with their actions in assumed sense. These assumed interpretations of the firm have something in common: they consider enterprise activity as the one based on the formation of a principally new productive force, which is not brought to any of resources bought at the market and this force is connected with creative activity of entrepreneurship 
subjects, managers may also be considered as such subjects.

Modern theoretical thought concerning the entrepreneurial activity works in a constructivist paradigm, considering creative ability of human knowledge to create reality. As a matter of fact, this means advancement in understanding human activity in general, but serves little in understanding a specific character of its special form, that is the entrepreneurial activity.

For the development of the entrepreneurial activity conception we suggest designing a value-based approach and we believe that the only subject in economy, responsible for value production, is an entrepreneur, no matter how he is called in specific historical conditions. It is value that is the sense, with which the entrepreneurial activity, as a special form of social action, is connected. The way of value formation is conviction in the value of produced goods and services by means of the integral system of entrepreneurial activity, a network of conviction guides, forming reliable social objects capable of convincing in their reality and value [26].

Conviction modus as central bodies of entrepreneurial action in their historical succession, on one hand, and synchronic coexistence, on the other, as well as value models corresponding to them must become a subject of entrepreneurship research founded on the value-based approach.

\section{Conclusion}

The analysis of the entrepreneurship conception and the entrepreneur figure on the basis of the personality traits theory showed that the entrepreneur is ascribed those characteristics of people which gradually become typical for the majority. This phenomenon we defined as entrepreneurship mystification based on personality traits.

Definitions of entrepreneurship based on its functions and «entrepreneurial spirit» mystify entrepreneurship attributing to it general activity characteristics, dealing with objective possibilities discovery and risks of their realization process. These characteristics of human activity, that are concerned with determinacy of possibilities and the probabilistic character of their recognition and realization are revealed only in entrepreneurship of the industrial period, but they are not included in its own specific character in comparison with other activity types.

New mystifications arise; entrepreneurship enters the period of designing new possibilities. On this foundation, representatives of the radical-subjectivistic trend of the economic thought determine various methods of the entrepreneurial design of activity and, as a consequence, new entrepreneurship interpretations, considering its cognitive and creative characteristics. But the latter, sooner or later, again become universal.

We suppose that all considered mystifications are due to the naturalistic approach to the entrepreneurial action vanishing its specific characteristics in the human action in general, even in case these characteristics are displayed in a proper way for the first time in the entrepreneurial activity. We suppose that the research of the social specific character of the entrepreneurial action is possible, if it is understood as a special kind of the social action, i.e. the action which, in its assumed sense, correlates with actions of others. In respect to the entrepreneurial action, it is value. In this case specifically historic definitions of entrepreneurship will differ only in modus of the value creation keeping social essence of the value creation process as the core. The revealing of the social process of the value formation and its modus, as well as definite models of the value itself implies the development and realization of the valuebased approach for the entrepreneurship research.

\section{Acknowledgment}

This work was performed by the authors in collaboration with Tomsk Polytechnic University within the project in «Development of a model of cross-regional cooperation in innovative activities», RFH project number № 16-0200492 .

\section{References}

1. J.A. Schumpeter, Capitalism, Socialism and Democracy (London, Routledge, 1994)

2. W.J. Baumol, Journal of Political Economy, 98(51), 894 (1990)

3. L.J. Fillion, Cahier recherché, 97(2), 7 (1997).

4. L. Boltanski, E. Chiapello, The new spirit of capitalism (London and New York, Verso, 2007).

5. W. Sombart, Studien zur Entwicklungsgeschichte des modernen Kapitalismus, Bd. I (Münch, Lpz., 1913)

6. K. Foss, N.J. Foss, P.G. Klein, Organization Studies, 28(1), 1893-1912 (2007)

7. N. Foss, P. Klein, The historical foundations of entrepreneurship research (Aldershot, UK, Edward Elgar, 2010)

8. T.H. Chiles, C.S. Tuggle, J. S.McMullen, L. Bierman, D.W. Organization Studies, 31(1), 7-46 (2010)

9. S.D. Sarasvathy, Academy of Management Review, 26(2), 243-263 (2001)

10. N.J. Foss, P.G. Klein, Y.Y. Kor, J.T. Mahoney Strategic Entrepreneurship Journal, 2(1), 73-94 (2008)

11. P. Dubini, H. Aldrich, Journal of Business Venturing, 6, 305-313 (1991)

12. G.L.S. Shackle, Time, Uncertainty and Disequilibrium (Lexington, Mass, Lexington Books, D. C. Heath and Co, M. J. Rizzo (ed), 1979)

13. N.J. Foss, G. Garzarelli, Cambridge Journal of Economics, 31(5), 789-804 (2007)

14. I. Szeman, The South Atlantic Quarterly, 114(3), $476(2015)$

15. A. Gorz, L'immatériel - Connaissance, valeur et capital (Paris, Galilée, 2003) 
16. P.G. Klein, M.L. Cook, Review of Agricultural Economics, 28(3), 344-350 (2006)

17. E. Gellner, Nations and Nationalism (Ithaca NY, Cornell University Press, 1983)

18. K.J. Foss, N.J. Foss, P.G. Klein, S.K. Klein, Journal of Management Studies, 44(7), 1167, 2007

19. L. Lachmann, Capital and its structure (Kansas City, MO, Sheed, Andrews, \&McMeel, 1956)

20. J. B. Barney, Journal of Management, 17(1), 99120 (1991)

21. R. Reed, R.J. DeFillippi, The Academy of Management Review, 15(1), 88-102 (1990)

22. S. Lippman, R.P. Rumelt, 1982. Bell Journal of Economics, 13(2), 418-438 (1982)

23. K.J. Foss, N.J. Foss, P.G. Klein, S.K. Klein, Journal of Management Studies, 44(7), 1167, (2007)

24. K.J. Foss, N.J. Foss, P.G. Klein, S.K. Klein, Journal of Management Studies, 44(7), 1165, 2007.

25. K. Foss, N.J. Foss, P.G. Klein, Organization Studies, 28(12), 1893-1912 (2007)

26. D.N. McCloskey, How Language Is Used to Do Business: Essays on the Rhetoric of Economics (Lewiston, NY, Mellen Press, 2008) 